\title{
BIOCONTROLE DE Macrophomina phaseolina E PROMOÇÃO DO CRESCIMENTO NA CULTURA DO GIRASSOL COM O USO DE Trichoderma Sp. E RIZOBACTÉRIAS
}

\section{BIOCONTROLE OF Macrophomina phaseolina AND PROMOTING GROWTH IN SUNFLOWER CULTURE WITH THE USE OF Trichoderma sp. AND RHYDROBACTERIA}

\author{
Nelrilene Pereira da Silva ${ }^{1}$; Marta Cristina Corsi de Filippi ${ }^{2}$; Fábio José Gonçalves ${ }^{3}$; Alan Carlos Alves \\ de Souza ${ }^{4 *}$
}

${ }^{1}$ Engenheira Agrônoma. Centro Universitário de Anápolis - UniEVANGÉLICA. neurilene.ps@hotmail.com

${ }^{2}$ Engenheira Agrônoma. Embrapa Arroz e Feijão. cristina.filippi@embrapa.br.

${ }^{3}$ Biólogo. Laboratório Agrolab.agrolabsementes@gmail.com.

${ }^{4}$ Engenheiro Agrônomo. Centro Universitário de Anápolis - UniEVANGÉLICA, curso de Agronomia.

alancarlosagro@gmail.com.

*Autor correspondente. Telefone: (62) 99248-5929.

\section{Info}

Recebido: 01/2021

Publicado: 03/2021

ISSN: $2595-6906$

DOI: 10.37951/2595-6906.2021v5i1.6544

Palavras-Chave
antagonismo, controle biológico, Helianthus
annuus
Keywords:
antagonism, biological control, Helianthus
annuus

\begin{abstract}
Resumo
Fungos fitopatogênicos habitantes do solo como Macrophomina phaseolina são de difícil controle, principalmente por formarem estruturas de resistência. Por se tratar de uma espécie polífaga, faz-se necessário realizar estudos para se obter diferentes formas efetivas de controle. Diante disso, o objetivo deste trabalho foi testar a eficiência de microrganismos benéficos no controle biológico de $\mathrm{M}$. phaseolina, e na promoção de crescimento à cultura do girassol. A presente pesquisa foi realizada em duas etapas, uma com ensaio in vitro e outra com ensaio in vivo. $\mathrm{O}$ ensaio in vitro foi conduzido no laboratório de análises microbiológicas AgroLab, onde realizou-se teste de pareamento de culturas com seis tratamentos e três repetições, sendo, (T1 - Trichoderma sp. + patógeno; T2 - Bacillus sp. + patógeno; T3 - B. pyrrocinia + patógeno; T4 - P. fluorescens + patógeno; T5 - B. subtilis + patógeno e T6 - somente o patógeno), avaliou-se a ocorrência de antibiose e selecionou-se os isolados mais promissores para o ensaio in vivo. $\mathrm{O}$ ensaio in vivo foi realizado na Unidade Experimental do laboratório AgroLab, em recipientes de $400 \mathrm{~mL}$, em cultivo protegido, sendo conduzido em Delineamento Inteiramente Casualizado com cinco tratamentos
\end{abstract} (T1 - controle; T2 - Trichodermil $\mathbb{R}$; T3 - Trichoderma sp.; T4 - B. pyrrocinia e T5 - B. subtilis) em oito repetições. Foram avaliados a capacidade dos bioagentes em suprimir a severidade da doença e, sua eficiência como promotores de crescimento para a cultura do girassol. Os parâmetros avaliados nas análises de crescimento foram: comprimento de raiz e parte aérea e, biomassa da raiz e parte aérea. Os resultados mostraram diferença significativa entre si pelo teste de $\mathrm{F}(\mathrm{p}<0,05)$. Nos testes in vitro, os isolados de Trichoderma sp., Bacillus subtilis e B. pyrrocinia reportaram melhor atividade antagônica com 10,93\%,10,26\% e 3,71\% de inibição do crescimento micelial do patógeno, respectivamente. Na promoção de crescimento todos os tratamentos promoveram maior comprimento da raiz e aumento da biomassa da parte aérea. Não houve diferença significativa para comprimento da parte aérea em relação a testemunha, e os isolados de B. subtilis, B. pyrrocinia e Trichoderma sp. apresentaram maior biomassa da

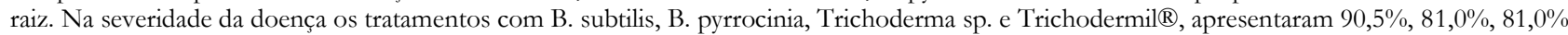
e 62,5\% de supressão do patógeno, respectivamente. Concluiu-se que estes microrganismos apresentam potencial como promotores de crescimento e biocontroladores da doença, podendo tornar-se técnica viável a ser inserida ao Manejo Integrado de Doenças. 


\section{INTRODUÇÃO}

Segundo Lourenço (2009), a busca por um modelo de agricultura mais sustentável é de extrema importância para o Brasil, pois o agronegócio contribui positivamente para as contas externas do país, sendo considerado o setor mais importante da nossa economia. Logo, deve ser conduzido sob padrões de sustentabilidade, para manutenção e preservação dessa riqueza.

A área da safra 20/21 é estimada em 65.109,8 mil ha, representando um incremento de 2,9\% na área plantada em comparação à safra passada ou uma variação absoluta de 1.847,6 mil ha, influenciado principalmente pelo crescimento das áreas de soja e milho. As culturas de primeira safra ocupam uma área de 45,5 mil ha, enquanto as culturas de segunda e terceira safras e de inverno são cultivadas em 19,6 mil ha, a maior parte aproveitando áreas já cultivadas. A Região Centro-Oeste é a principal produtora de girassol, sendo o Estado de Goiás o maior responsável por esse cultivo (CONAB, 2020).

A cultura do girassol está entre as principais espécies vegetais com potencial para a produção de energia renovável no Brasil. Por ser uma oleaginosa que produz alto teor de óleo de boa qualidade, configura-se como uma importante fonte de matéria-prima para a produção de óleo comestível e biocombustível (OLIVEIRA et al., 2018). Tem importante papel na alimentação humana e animal, e é uma cultura com elevado potencial ornamental, dentre as flores tropicais, destaca-se por possuir altura de hastes variadas e belas inflorescências com cores diversas, dependendo da variedade (ZOBIOLE et al., 2010).

Apresenta características desejáveis do ponto de vista agronômico, como ciclo curto, ampla adaptabilidade às diferentes condições edafoclimáticas, rusticidade e resistência a déficits hídricos, podendo ser cultivada em todas as regiões do País, pois o rendimento é pouco influenciado pelas latitudes e altitudes, assim como pelo fotoperíodo, o que facilita a expansão do cultivo no Brasil (CASTRO et al., 2005).

No entanto, de acordo com Lazzarotto et al., (2005) a expansão da cultura do girassol no país pode ser prejudicada, pela ocorrência de doenças causadas por fungos, bactérias, vírus e nematóides, devido apresentar climas que favorecem o desenvolvimento desses patógenos, e seu controle pode ser considerado de alto custo, levando os produtores a dar preferência para culturas com maiores rendimentos, a exemplo, soja e milho.

A importância dessas doenças pode variar anualmente dependendo de condições climáticas que favoreçam a ocorrência e o processo infectivo de determinados patógenos. De modo geral, as doenças ocorrem com maior intensidade nessa cultura a partir do florescimento, e as mais comuns são mancha de alternária (Alternaria helianthi); mofo branco (Sclerotinia sclerotiorum); ferrugem (Puccinia helianthi Schw.); oídio (Erysiphe cichoracearum); mancha preta da haste (Phoma oleracea var. helianthi tuberosi Sacc.) e a podridão negra (Macrophomina phaseolina (Tass.) Goid.), sendo esta, muito estudada devido ao grande número de culturas que é capaz de causar danos (SU et al., 2001; RIBEIRO, 2008; SANTOS et al., 2014).

Fungos fitopatogênicos habitantes do solo, como Macrophomina phaseolina, são de difícil controle, principalmente por formarem estruturas de resistência, os microesclerócios. A eliminação ou redução de alguns microrganismos tem sido eficientemente alcançada por tratamentos químicos (DOMENE et al., 2016), porém, para esta doença este método não tem sido efetivo, nem economicamente viável, e levando em consideração que M. phaseolina é um fungo cosmopolita e patogênico de diferentes espécies, o que facilita a disseminação da doença, uma vez que pode sobreviver em culturas como o amendoim, girassol, morango, soja, milho, entre outras espécies cultivadas e também algumas invasoras, a rotação de culturas e o uso de controle químico nem 
sempre são uma alternativa para diminuir a fonte de inóculo, podendo ser utilizado o controle biológico, incluindo-o ao manejo integrado da doença (LINHARES et al., 2015).

Alguns fungos do gênero Trichoderma, são registrados como agentes de biocontrole para um grande número de patógenos e como promotores de crescimento de plantas (YEDIDIA et al., 2003). A compatibilização da produção agrícola, conservação ambiental e a segurança alimentar tornaram-se o grande desafio deste século, o que tem como princípio a integração dos fatores biológicos nos sistemas de produção (PATERNIANI, 2001). Com isso, tem aumentado o uso de microrganismos, como o Trichoderma sp., e as rizobactérias promotoras de crescimento, que podem resultar no acúmulo de biomassa, na supressão de doenças, aumento da produtividade no campo e redução do uso de defensivos químicos (GHINI et al., 2000; SOTTERO et al., 2006).

Diante disso, o objetivo deste trabalho foi avaliar a eficiência de um isolado de Trichoderma, e algumas rizobactérias na supressão da podridão negra da raiz (Macrophomina phaseolina) e a promoção de crescimento na cultura do girassol em cultivo protegido.

\section{MATERIAL E MÉTODOS}

Foram realizados dois ensaios: in vitro e in vivo. O objetivo do ensaio in vitro foi testar o antagonismo de bioagentes perante o patógeno Macrophomina phaseolina e selecionar os melhores microrganismos para a realização do ensaio in vivo. O objetivo do ensaio in vivo foi avaliar os bioagentes selecionados na promoção de crescimento e supressão da doença em plantas de girassol.

\subsection{Ensaio in vitro}

\subsection{1 - Delineamento experimental}

A presente pesquisa foi realizada no Laboratório de Análises Microbiológicas AgroLab, localizado em Goiânia-GO. Utilizou-se um isolado de Trichoderma e quatro rizobactérias para testar sua eficiência como antagonistas a Macrophomina phaseolina. Todos os microrganismos utilizados na pesquisa, inclusive o patógeno, são provenientes da coleção de microrganismos multifuncionais do laboratório AgroLab.

O ensaio foi conduzido utilizando a técnica de pareamento de culturas em placas de Petri contendo meio de cultura BDA (batata, dextrose e ágar), conforme descrito por Dennis; Webster (1971). O teste foi composto por um total de cinco tratamentos (antagonistas) e a testemunha (patógeno cultivado na ausência do antagonista), com três repetições, em Delineamento Inteiramente Casualizado. Os tratamentos foram: T1 - Trichoderma sp. + patógeno; T2 - Bacillus sp. + patógeno; T3 - Burkholderia pyrrocinia + patógeno; T4 - Pseudomonas fluorescens + patógeno; T5 Bacillus subtilis + patógeno e T6 - somente o patógeno M. phaseolina.

\subsection{2 - Montagem dos testes}

Para a montagem dos testes, o patógeno $M$. phaseolina foi cultivado em placa de Petri com meio BDA e incubado em câmara de crescimento do tipo BOD por um período de dez dias, com fotoperíodo de $12 \mathrm{~h}$ e temperatura de $28^{\circ} \mathrm{C}$. Para testar a eficiência do isolado fúngico de Trichoderma sp., previamente conservado em papel celofane, pareou-se na mesma placa de Petri um disco de micélio, de $0,5 \mathrm{~cm}$ de diâmetro, de $M$. phaseolina (previamente cultivada) com um pedaço de papel celofane de Trichoderma sp. com 0,5 $\mathrm{cm}$ de diâmetro. Ambas as estruturas foram colocadas a $1,5 \mathrm{~cm}$ da borda da placa, contendo $20 \mathrm{~mL}$ do meio de cultura BDA, em lados opostos.

Para o teste de antagonismo das rizobactérias, os isolados bacterianos foram multiplicados em 
Erlenmeyers contendo $100 \mathrm{~mL}$ do meio de cultura líquido caldo nutriente, os quais foram colocados em mesa agitadora na velocidade de $110 \mathrm{rpm}$ por 48 horas. Em seguida, as suspensões multiplicadas foram padronizadas com o auxílio de um espectrofotômetro e ajustadas com comprimento de onda de 540 nanômetros e 0,5 de absorbância, obtendo a concentração de $1 \times 10^{8}$ UFC.mL-1. Posteriormente, foram adicionados $100 \mu \mathrm{L}$ da suspensão padronizada de cada isolado bacteriano em placa de Petri $(9 \mathrm{~cm}$ de diâmetro) contendo $20 \mathrm{~mL}$ do meio de cultura BDA e, com o auxílio de uma alça de platina, foram feitas quatro estrias em sentidos opostos na mesma placa, uma com cada bactéria, a 1,5 cm da borda. Em seguida, um disco de micélio de $0,5 \mathrm{~cm}$ de diâmetro do fitopatógeno $M$. phaseolina foi colocado no centro da placa.

No caso da testemunha, transferiu-se para o centro das placas de Petri, contendo meio BDA um disco de $0,5 \mathrm{~cm}$ de diâmetro do fitopatógeno $M$. phaseolina. Todas as placas foram incubadas em câmara de crescimento do tipo BOD por 8 dias, na temperatura de $28^{\circ} \mathrm{C}$, com fotoperíodo de $12 \mathrm{~h}$ (ETHUR et al., 2005).

\subsection{3 - Avaliação dos testes}

As avaliações foram realizadas aos 8 dias após a incubação, medindo-se o diâmetro da área de crescimento micelial do patógeno M. phaseolina em cada repetição. A partir dos resultados obtidos, foram selecionados aqueles isolados que demonstraram o melhor desempenho em relação ao percentual de redução de crescimento micelial do patógeno.

\subsection{Ensaio in vivo}

\subsubsection{Delineamento experimental}

Os testes in vivo foram realizados na Unidade Experimental do Laboratório de Análises Microbiológicas AgroLab, localizado nas coordenadas geográficas de latitude $16^{\circ} 40^{\prime} 48^{\prime \prime}$ Sul e longitude $49^{\circ}$
15' 18" Oeste, com altitude de 749m. O clima da região é classificado de acordo com Köppen, como Aw (tropical com estação seca). A temperatura média anual é de $24.9^{\circ} \mathrm{C}$ e a pluviosidade média anual de $1924 \mathrm{~mm}$, com chuvas de outubro a abril.

O experimento foi conduzido em delineamento inteiramente casualizado, sendo cinco tratamentos previamente determinados e selecionados no ensaio in vitro, consistindo em: T1 - controle; T2 Trichodermil ${ }^{\mathbb{R}}$; T3 - Trichoderma sp.; T4 - Burkbolderia pyrrocinia e T5 - Bacillus subtilis, com oito repetições, sendo que quatro foram utilizados para avaliação da promoção do crescimento e quatro utilizou-se para avaliar a ocorrência e severidade da doença.

O ensaio foi realizado em condições de cultivo protegido com telado utilizando recipientes de plástico descartáveis $(400 \mathrm{~mL})$ com substrato comercial Ouro Negro $^{\circledR}$ (esterco de gado e de aves, húmus de minhoca, bokashi e casca de pinus). Foram semeadas duas sementes por repetição, deixando apenas uma planta, com desbaste realizado aos 14 dias após o plantio. A cultivar de girassol utilizada foi a BRS 324.

\subsection{2 - Aplicação dos tratamentos}

Para o preparo da suspensão utilizada nos tratamentos com o Trichoderma sp., o isolado foi multiplicado em placas de Petri contendo meio de cultura BDA. As placas foram incubadas em câmara de crescimento do tipo BOD por 8 dias, na temperatura de $28{ }^{\circ} \mathrm{C}$, com fotoperíodo de $12 \mathrm{~h}$. Após isso, as placas foram lavadas com água destilada, com o auxílio de uma alça de Drigalski, obtendo-se a suspensão, a qual foi ajustada para a concentração de $3,0 \times 10^{5}$ conídios viáveis $\mathrm{mL}^{-1}$ por meio de uma câmara de Neubauer em microscópio óptico (SOUZA et al., 2015).

Para o preparo da suspensão com as rizobactérias, os isolados bacterianos foram multiplicados em Erlenmeyers contendo $100 \mathrm{~mL}$ do meio de cultura líquido caldo nutriente, os quais foram 
colocados em mesa agitadora na velocidade de 110 RPM por 48 horas. Em seguida, as suspensões multiplicadas foram padronizadas com o auxílio de um espectrofotômetro e ajustadas com comprimento de onda de 540 nanômetros e 0,5 de absorbância, obtendo a concentração de $1 \times 10^{8}$ UFC.mL-1 (SOUZA et al., 2015).

A aplicação das suspensões foi realizada no momento do plantio, através do tratamento das sementes, na dosagem de $500 \mathrm{~mL}$ das suspensões para $100 \mathrm{Kg}$ de sementes e, uma pulverização foliar aos 14 dias após o plantio, com dosagem de $200 \mathrm{~mL} \mathrm{ha-}{ }^{1}$ com o auxílio de um pulverizador manual. O produto biológico comercial utilizado foi o Trichodermil ${ }^{\circledR}$ SC 1306 (Trichoderma harzianum), aplicado da mesma forma e dosagem que os tratamentos anteriores.

\subsection{3 - Inoculação do patógeno e avaliação} da doença

A inoculação do patógeno ocorreu artificialmente através da técnica do palito, aos 21 dias após o plantio, espetando-se o palito colonizado na haste das plantas sem atravessá-la totalmente, cerca de $1 \mathrm{~cm}$ abaixo do nó cotiledonar. Para obtenção dos palitos colonizados, utilizou-se palitos-de-dente de madeira de pinus de formato cilíndrico, os quais foram fervidos com duas trocas de água para eliminar a resina e, depois de secos, foram cortados em $1 / 4$ do tamanho normal e apontados em uma das extremidades. Em seguida foram colocados nas placas de Petri e esterilizados em autoclave por $30 \mathrm{~min}$ a $120^{\circ} \mathrm{C}$ e $1 \mathrm{~atm}$. O meio de cultura BDA foi vertido na placa de Petri contendo cerca de 60 palitos por placa e, a quantidade de meio de cultura foi distribuída de forma que apenas 3 a $4 \mathrm{~mm}$ da extremidade afinada do palito, na posição vertical, ficasse fora do meio. Após a solidificação do meio, o fungo foi repicado sobre o BDA e as placas foram incubadas a temperatura de $30^{\circ} \mathrm{C}$ durante 10 dias, até os palitos serem totalmente colonizados pelo fungo (TESSO; EJETA, 2011). O experimento foi mantido em telado sendo irrigado de dois em dois dias.

As avaliações de ocorrência da doença foram efetuadas determinando a severidade, aos 8 dias após a inoculação e, a Área Abaixo da Curva de Progresso da Doença (AACPD), aos 2, 4 e 8 dias após a inoculação com o patógeno. Para a avaliação empregou-se uma escala de notas, adaptada de Abawi (1990), com variação de 1 a 9, onde $1=$ ausência de sintomas visíveis; 3 = discreta lesão necrótica a até 10\% do hipocótilo com lesões superficiais; $5=$ aproximadamente $25 \%$ do hipocótilo apresentando lesões necróticas; $7=$ aproximadamente $50 \%$ do hipocótilo lesionada, com percepção discreta das estruturas fúngicas e $9=$ aproximadamente $75 \%$ ou mais dos tecidos do hipocótilo apresentando lesões, sendo observado intenso crescimento fúngico. Os valores da severidade média obtidos foram utilizados para o cálculo da AACPD, conforme metodologia de Campbell e Madden (1990).

\subsection{4 - Avaliação da promoção de}

\section{crescimento}

As avaliações da promoção de crescimento foram realizadas aos dezoito dias após a semeadura. Os parâmetros avaliados nas análises de crescimento foram: comprimento de raiz e parte aérea e biomassa de raiz e parte aérea. Efetuou-se a medida do comprimento da parte aérea das plantas e da parte radicular com auxílio de régua milimétrica, em seguida com uma tesoura, separou-se a raiz da parte aérea e as plantas foram acondicionadas em sacos de papel e colocadas em estufa por 72 horas a $60^{\circ} \mathrm{C}$ para a secagem. Depois de secas, cada amostra foi pesada separadamente em balança de precisão, determinando a biomassa.

\section{3 - Análise estatística}

Todos os dados obtidos nos dois ensaios foram submetidos à análise de variância e teste de 
Tukey a 5\% de probabilidade. Utilizou-se o software SPSS versão 21.0 como auxílio na análise.

\section{RESULTADOS E DISCUSSÃO}

\section{1. Ensaio in vitro}

De acordo com os resultados obtidos (Tabela 1), observou-se diferença significativa entre os tratamentos utilizados. O tratamento controle contendo somente o patógeno $M$. phaseolina apresentou crescimento micelial de $90 \mathrm{~mm}$, demonstrando que houve condições favoráveis para o desenvolvimento do mesmo. Os tratamentos contendo os isolados de Trichoderma sp. e Bacillus subtilis se destacaram dos demais, apresentando crescimento micelial do patógeno de $80,16 \mathrm{~mm}$ e $80,76 \mathrm{~mm}$, com $10,93 \%$ e $10,26 \%$ de inibição de $M$. phaseolina em relação ao tratamento controle, respectivamente, reportando melhor atividade antagônica. A bactéria Burkholderia pyrrocinia também se mostrou eficiente estatisticamente, apresentando 86,66 mm de crescimento micelial do patógeno, com 3,71\% de inibição em relação ao tratamento controle (Tabela $1)$.

Tabela 1 - crescimento micelial (mm) de colônias de Macrophomina phaseolina em função da ação inibitória de diferentes microrganismos antagonistas em meio BDA.

\begin{tabular}{cc} 
Tratamentos & Crescimento Micelial (mm) \\
\hline M. phaseolina & $90,00 \mathrm{c}$ \\
Pseudomonas fluorescens $\times$ M. phaseolina & $90,00 \mathrm{c}$ \\
Bacillus sp. $\times$ M. phaseolina & $90,00 \mathrm{c}$ \\
Burkholderia pyrrocinia $\times$ M. phaseolina & $86,66 \mathrm{~b}$ \\
Bacillus subtilis $\times$ M. phaseolina & $80,76 \mathrm{a}$ \\
Trichoderma sp. $\times$ M. phaseolina & $80,16 \mathrm{a}$ \\
\hline CV (\%) & 2,97
\end{tabular}

*Médias seguidas pelas mesmas letras não diferem entre si pelo teste de Tukey ( $\mathrm{P}>5 \%$ ).

De acordo com Carvalho et al. (2011), o Trichoderma sp. está entre os antagonistas mais utilizados contra patógenos do solo, pois são capazes de inibir o desenvolvimento de vários desses fitopatógenos. Segundo Machado et al. (2012), essa capacidade é devido a sua versatilidade de ação, como parasitismo, antibiose e competição. Dias (2011), avaliando o potencial de doze isolados de Trichoderma na inibição de patógenos de solo, (Sclerotium rolfsii em tomateiro, Rhizoctonia solani na cultura da alface e Fusarium oxysporum f.sp. phaseoli no feijoeiro-comum, constatou que todos os isolados testados apresentaram capacidade em inibir o crescimento de pelo menos um dos patógenos e, em alguns casos, o antagonista chegou a ocupar $100 \%$ da distância entre as colônias.

Corroborando com os resultados obtidos, Amaral (2018), testou diferentes isolados de Trichoderma e obteve resultados positivos, onde três isolados da espécie $T$. atroviride inibiram o crescimento micelial de todos os cinco isolados de $M$. phaseolina avaliados.

As bactérias do gênero Bacillus spp. se destacam como bactérias antagonistas por formarem endósporo e apresentarem uma multiplicidade de mecanismos antagônicos (LANNA FILHO et al., 2010). Bactérias antagônicas, como B. subtilis, de modo geral agem significativamente por antibiose e, ocasionalmente, por parasitismo e competição. Estudos realizados por Chen et al. (2008), revelaram que $B$. subtilis é capaz de produzir substâncias voláteis com atividade antifúngica, o que pode ser um dos fatores que contribuíram neste caso, para que fosse um dos tratamentos mais eficientes na inibição do crescimento micelial de $M$. phaseolina. 
Não foram encontrados relatos na literatura de resultados em que, a bactéria Burkholderia pyrrocinia tenha sido testada como antagonista à Macrophomina, no entanto, em pesquisa realizada por Massenssini et al. (2016), um isolado do gênero Burkholderia, inibiu severamente o crescimento radial da colônia de Pisolithus sp., levando à produção de micélio aéreo pouco denso. Bach (2016), testando isolados de diferentes microrganismos antagonistas, constatou que a Burkholderia sp. se destacou entre os demais tratamentos pela produção de um metabólito estável com ampla atividade contra fungos fitopatogênicos, apresentando atividades antagônicas contra patógenos. Devido aos resultados positivos, os isolados de Trichoderma sp., Bacillus subtilis e Burkholderia pyrrocinia foram escolhidos para a realização do teste in vivo.

\subsection{Ensaio in vivo}

\subsubsection{Promoção de crescimento}

Os tratamentos testados na promoção de crescimento mostraram diferença significativa entre si (Tabela 2). Em relação ao parâmetro comprimento de parte aérea, nenhum dos tratamentos utilizados diferiram estatisticamente do tratamento controle, constatando que não houve diferença no crescimento da parte aérea das plantas.

Para o parâmetro comprimento de raiz, as plantas mostraram melhor desenvolvimento nos tratamentos contendo Trichodermil ${ }^{\circledR}$, Trichoderma sp., B. subtilis e B. pyrrocinia, apresentando 33,66\%, 27,06\%, $26,07 \%$ e 23,43\% de aumento no crescimento das raízes em relação ao tratamento controle, respectivamente. Quanto à biomassa das raízes, observou-se que o tratamento contendo a bactéria Burkholderia pyrrocinia destacou-se dos demais, com 259,23\% a mais de biomassa em relação ao tratamento controle, seguido dos tratamentos com a bactéria Bacillus subtilis, com 176,92\% e, com o isolado de Trichoderma sp. com aumento de $76,92 \%$ da biomassa em relação à testemunha. Para a biomassa da parte aérea as plantas tratadas com B. pyrrocinia, B. subtilis, Trichoderma sp. e Trichodermil ${ }^{\circledR}$, obtiveram 420,48\%, 369,87\%, 153,01\% e $48,19 \%$ de aumento da biomassa em relação ao tratamento controle, respectivamente.

Tabela 2- Avaliação da promoção de crescimento, dado pelo teste de médias, considerando comprimento de raiz e parte aérea e, biomassa de raiz e parte aérea, realizada no décimo oitavo dia após a semeadura em plantas de girassol, em condições de telado.

\begin{tabular}{ccccc}
\hline \multirow{2}{*}{ Tratamentos } & \multicolumn{2}{c}{ Comprimento $\mathbf{( c m )}$} & \multicolumn{2}{c}{ Biomassa (g) } \\
\cline { 2 - 5 } & Raiz & Parte Aérea & Raiz & Parte Aérea \\
\hline Controle & $15,15 \mathrm{~b}$ & $7,60 \mathrm{a}$ & $0,0130 \mathrm{c}$ & $0,0083 \mathrm{c}$ \\
Trichodermil ${ }^{\circledR}$ & $20,25 \mathrm{a}$ & $6,70 \mathrm{a}$ & $0,0162 \mathrm{c}$ & $0,0123 \mathrm{bc}$ \\
Trichoderma sp. $_{\text {surkbolderia pyrrocinia }}^{19,25 \mathrm{a}}$ & $7,30 \mathrm{a}$ & $0,0230 \mathrm{bc}$ & $0,0210 \mathrm{~b}$ \\
Bacillus subtilis & $18,70 \mathrm{a}$ & $7,02 \mathrm{a}$ & $0,0467 \mathrm{a}$ & $0,0432 \mathrm{a}$ \\
CV (\%) & $19,10 \mathrm{a}$ & $6,62 \mathrm{a}$ & $0,0360 \mathrm{ab}$ & $0,0390 \mathrm{a}$ \\
\hline
\end{tabular}

*Médias seguidas pelas mesmas letras, na coluna, não diferem entre si pelo teste de Tukey ( $\mathrm{P}>5 \%$ ).

Diversos microrganismos que vivem na rizosfera se associam às raízes das plantas e podem auxiliar em uma série de processos que resultam no melhor desenvolvimento das culturas agrícolas. Dentre eles estão fungos benéficos e as rizobactérias promotoras de crescimento de plantas (BPCP) (LUVIZOTTO, 2008).
Segundo Parret et al. (2003), as rizobactérias que habitam as plantas estão expostas a microambientes altamente competitivos, onde os microrganismos presentes competem por nutrientes e pela ocupação do nicho ecológico. Este fato interfere nos resultados da interação das BPCPs com as plantas, ocasionando diferentes resultados para cada espécie. 
As rizobactérias, como as do gênero Burkholderia, apresentam grande potencial para adaptarem-se à nichos ocupados e promoverem maior nutrição e sanidade às plantas, por serem descritas como bactérias diazotróficas endofíticas (que habitam o interior do tecido vegetal), e também rizosféricas (habitantes da fina camada de solo aderente às raízes). Geralmente as bactérias deste gênero são capazes de fixar nitrogênio atmosférico, solubilizam fosfato inorgânico, são produtoras de fitohormônios como AIA, sideróforos, enzimas e apresentam capacidade de produzir compostos com atividade antimicrobiana (YABUUCHI et al., 1992; REIS et al., 2004; LUVIZOTTO, 2008).

Em pesquisa realizada por Lopes et al. (2018), utilizando Burkholderia pyrrocinia em solos cultivados com Brachiaria brizantha para avaliar a produção de biomassa da gramínea, constataram o aumento na produção de biomassa, nos teores de nitrogênio, nitrato e proteína. Baldotto et al. (2010), avaliando o desempenho inicial do abacaxizeiro 'Vitória' propagado por cultura de tecidos, em resposta à aplicação de ácidos húmicos isolados de vermicomposto e Burkholderia spp., verificaram que essa associação resultou em maior massa da parte aérea e raiz e maior conteúdo de nutrientes (N, $132 \%$; $131 \%$ K, $80 \%$ quando comparado com mudas não inoculadas.

Segundo Gray e Smith (2005), bactérias do gênero Bacillus, inoculadas isoladamente ou em consórcio com estirpes de Rhizobium ou Bradyrbizobium, aumentam o crescimento vegetal de leguminosas. Santos et al. (2014), realizaram testes em casa de vegetação para determinar o efeito da inoculação de bactérias do gênero Bacillus sobre o crescimento e teores de nutrientes e de solutos orgânicos, em folhas e raízes de girassol sob estresse hídrico e, as bactérias incrementaram o crescimento das plantas e também aumentaram a capacidade das plantas, sob estresse hídrico, realizarem o ajustamento osmótico pelo maior acúmulo de solutos orgânicos, quando comparadas com as plantas não inoculadas.

Da Silva et al. (2019), constataram que sementes de três cultivares de girassol inoculadas com Bacillus sp. apresentaram maior taxa de germinação e crescimento de plântulas. Em pesquisa realizada por De Sá et al. (2019a), um isolado de Bacillus subtilis influenciou positivamente a germinação e o crescimento inicial de feijão caupi, promovendo aumento significativo na massa seca da parte aérea e da raiz.

De acordo com Silveira (2008), a promoção do crescimento radicular é um dos marcadores pelo qual o efeito benéfico das BPCPs é medido, promovendo em diversos casos o aumento no comprimento das raízes primárias e o acréscimo de raízes laterais e adventícias, sendo favorecido pela presença de AIA, podendo ser vantajoso para plantas jovens. Conforme Srinivasan et al. (1996), Bacillus spp. isolados da rizosfera de Phaseolus vulgaris, produziram quantidades significativas de AIA, promovendo o crescimento das raízes de plantas de feijoeiro. O que pode ter levado o Bacillus subtilis, do presente estudo, a contribuir para o aumento significativo do comprimento e da biomassa das raízes das plantas de girassol.

Fungos benéficos também podem proporcionar diversas vantagens relacionadas com a promoção do crescimento de plantas. Vários autores citam em suas pesquisas algumas espécies do gênero Trichoderma atuando na promoção de crescimento de uma gama de culturas através de diferentes mecanismos como por exemplo, a melhoria na absorção de nutrientes (LUCON, 2009; CARVALHO et al., 2011; PEDRO et al., 2012; HOFFMANN et al., 2015).

Segundo Harman et al. (2004), os fungos do gênero Trichoderma, produzem metabólitos secundários de importante ação na promoção de crescimento de plantas, para eles a colonização radicular por fungos 
desse gênero frequentemente aumenta o crescimento e desenvolvimento da raiz, incrementa a produtividade das culturas, induz a resistência a estresses abióticos e auxilia na absorção e utilização de nutrientes. Tais resultados corroboram com os obtidos nesta pesquisa, quando é possível observar que tanto o isolado de Trichoderma quanto o produto comercial promoveram um maior comprimento das raízes.

Os isolados de Trichoderma spp. mais eficientes em pesquisa realizada por Pedro et al. (2012), proporcionaram aumentos superiores a 30\% na produção de matéria seca da parte aérea das plantas. Silva et al. (2011), avaliando o potencial de diferentes isolados de Trichoderma, constataram que dezenove isolados e o produto comercial Trichodermil ${ }^{\circledR}$ promoveram o crescimento da parte aérea e radicular de pepineiro em até $100 \%$.

\subsubsection{Supressão da doença}

Em relação à severidade da doença, observou-se que os tratamentos utilizados via tratamento de sementes e pulverização foliar com Bacillus subtilis, Burkholderia pyrrocinia, Trichoderma sp. e Trichodermil ${ }^{\circledR}$ mostraram eficiência na supressão da Macrophomina phaseolina, apresentando 90,5\%, 81\%, 81\% e $62,5 \%$ de supressão da doença em relação ao tratamento controle, respectivamente (Tabela 3).

Tabela 3- Avaliação da severidade de M. phaseolina em plantas de girassol aos oito dias após a inoculação, em condições de telado.

\begin{tabular}{cc}
\hline Tratamentos & Severidade (\%) \\
\hline Controle & $53,50 \mathrm{~b}$ \\
Trichodermil $^{\circledR}$ & $20,00 \mathrm{a}$ \\
Trichoderma sp. & $10,00 \mathrm{a}$ \\
Burkholderia pyrrocinia & $10,00 \mathrm{a}$ \\
Bacillus subtilis & $5,00 \mathrm{a}$ \\
\hline CV (\%) & $\mathbf{7 , 2 1}$
\end{tabular}

*Médias seguidas pelas mesmas letras não diferem entre si pelo teste de Tukey $(\mathrm{P}>5 \%)$.

Para a Área Abaixo da Curva de Progresso da Doença (AACPD), os tratamentos com Bacillus subtilis, Burkholderia pyrrocinia e Trichoderma sp. se destacaram com 89,2\%, 83,2\% e 69,4\% de supressão da doença em relação ao tratamento controle, respectivamente (Figura 3A). A partir da observação do comportamento da doença durante os oito dias após a inoculação, foi possível perceber o efeito positivo dos demais tratamentos em relação ao tratamento controle, apresentando menor progresso da doença aos 2,4 e 8 dias após a inoculação (Figura 3B).

As RPCPs proporcionam benefícios relacionados ao controle de doenças de plantas que podem ser verificados em diversas culturas, sendo resultado de mecanismos como controle biológico pela competição por nutrientes com o patógeno, produção de sideróforos e antibióticos e ainda, a resistência induzida a doenças (SOT'TERO et al., 2006). Muitas linhagens de B. subtilis produzem lipopeptídeos, que são compostos orgânicos com atividades surfactante e antimicrobiana. A produção desses compostos, associada à capacidade de formação de esporos, contribui para a utilização comercial desta espécie como controlador biológico de várias doenças de plantas (DE OLIVEIRA; SOUTO, 2006).

Isolados de bactérias Bacillus sp. foram eficientes no controle do fungo Macrophomina phaseolina 
em testes in vitro realizados por Marroni; Germani (2011). Segundo Moreira (2013), o produto comercial a base de Bacillus subtilis (Serenade ${ }^{\circledR}$ ), em testes para controle de antracnose na cultura da maçã, evidenciou a produção de compostos antifúngicos termoestáveis nos testes in vitro, contribuindo para uma evolução mais lenta do número de lesões da antracnose em mudas de macieira Gala, quando comparada aos outros tratamentos.
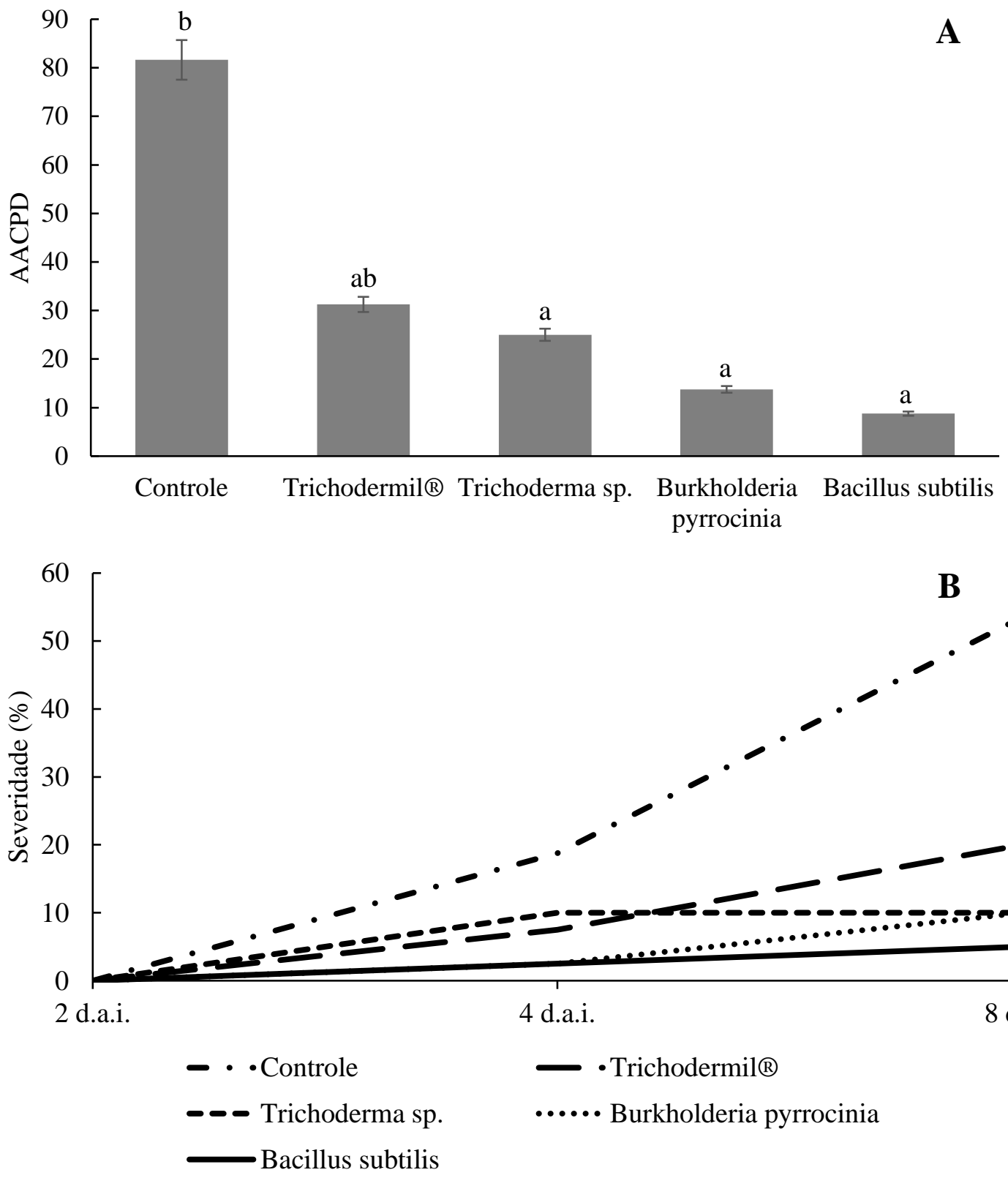

Figura 3 - Área Abaixo da Curva de Progresso da Doença (AACPD) em plantas de girassol com avaliações aos 2, 4 e 8 dias após a inoculação (d.a.i.) (A). Progresso da severidade (\%) da Macrophomina phaseolina em plantas de girassol aos 2, 4 e 8 dias após a inoculação (d.a.i.) (B). Teste de Tukey a 95\% de significância. Goiânia - Goiás.

Avaliando a compatibilidade entre (2010), observaram que a combinação de um isolado de rizobactérias biocontroladoras pré-selecionadas e o Bacillus sp. com um isolado não identificado efeito de suas combinações sobre a queima-das-bainhas (DFs306/416) proporcionou os melhores resultados (Rhizoctonia solani) e a meloidoginose (Meloidogyne para o controle das duas doenças. Ferreira (2019), graminicola) na cultura do arroz, Souza Júnior et al. realizou uma revisão de bibliografia reunindo novas 
informações acerca da melhoria da sanidade e da nutrição de plantas de milho pelo auxílio de isolados do gênero Bacillus, e concluiu que diversos isolados de Bacillus sp. podem ser úteis por promoverem a sanidade, em relação a patógenos de solo, e a melhoria da nutrição aos plantios de milho, corroborando com os resultados obtidos neste trabalho.

Bach (2016), através de análises de espectrometria comprovou-se que isolados de Burkholderia sp. produzem diferentes variantes de antifúngicos, conferindo a este gênero um potencial biotecnológico com possíveis aplicações farmacêuticas e agronômicas para o biocontrole de fungos fitopatogênicos. Brito et al. (2018), ao avaliarem isolados de Burkholderia sp. em ação antagonista a $M$. phaseolina, relataram que o patógeno teve o desenvolvimento inibido em 26\% pela bactéria.

Espécies de Trichoderma tem despertado interesse científico e vem sendo aplicadas como agentes de controle biológico devido sua ação antagonista a diversos fitopatógenos através de competição, parasitismo, antibiose e a importante ação de metabólitos secundários produzidos por estes fungos benéficos na indução de resistência. Muitas espécies deste gênero são capazes de produzir substâncias antifúngicas e também enzimas que degradam paredes celulares de outros fungos, além de apresentarem diversidade estratégica de sobrevivência, o que os torna altamente competitivos no ambiente, garantindo grande capacidade de proliferação na rizosfera (POMELLA; RIBEIRO, 2009; ASAD et al. 2015).

Corroborando com os resultados obtidos nesta pesquisa, em testes realizados por Amaral (2018), um isolado de Trichoderma atroviride chegou a reduzir em mais de $50 \%$ o número de plantas com sintomas em variedade de feijão inoculada com Macrophomina phaseolina. Menezes et al. (2013), testaram quatro isolados de espécies diferentes de Trichoderma para avaliar a supressão da $M$. phaseolina em feijão utilizando duas metodologias, o tratamento do solo e o tratamento das sementes com os antagonistas, e todos os isolados mostraram potencial no controle do fitopatógeno inoculado tanto nas sementes quanto no solo. Das quatro espécies estudadas, o Trichoderma harzianum mostrou melhor resultado em ambos os tratamentos, indicado pelo maior percentual de plantas sobreviventes.

\section{CONCLUSÃO}

Os isolados de Bacillus subtilis, Burkholderia pyrrocinia e Trichoderma sp. foram capazes de inibir o crescimento micelial do fungo $M$. phaseolina em testes in vitro, promover o crescimento das plantas e suprimir a severidade da doença em condições de casa de vegetação, sugerindo que essas espécies têm potencial para serem introduzidas ao Manejo Integrado de Doenças, utilizadas para promoção de crescimento e melhoria da sanidade das plantas. A utilização de inoculantes contendo microrganismos com potencial para promover o crescimento e/ou o controle biológico de doenças no cultivo de girassol é uma alternativa sustentável, e que pode contribuir para o aumento da produção dessa oleaginosa no Brasil.

\section{REFERÊNCIAS}

ABAWI, G.S. Root rots of beans in Latin America and Africa: diagnoses, research methodologies and management strategies. n. 35. Colômbia. Ciat. 1990.

AMARAL, A. C. T. DO. Biocontrole de espécies de Trichoderma sobre Macrophomina phaseolina e Sclerotinia sclerotiorum. Dissertação de Mestrado, 2018. Disponível em: https://repositorio.ufpe.br/handle/123456789 /32892. Acesso em: 13/05/2020.

ASAD, S.A.; TABASSUM, A.; HAMEED, A.; HASSAN, F.U. L; AFZAL, A.; KHAN, S. A.; AHMED, R.; SHAHZAD, M. Determination of lytic enzyme activities of indigenous Trichoderma isolates from Pakistan. Brazilian Journal of Microbiology, v. 46 n. 4 p. 1053-1064, 2015. 
BACH, E. Utilização de Burkholderia sp. para o controle biológico de fungos fitopatogênicos e identificação de moléculas de seu metabolismo secundário envolvidas nesse processo. 2016. Disponível em: http://go.microsoft.com/fwlink/p/?LinkId/25 5141. Acesso em: 15/05/2020.

BALDOTTO, L. E. B.; BALDOTTO, M. A.; CANELLAS, L. P.; BRESSAN-SMITH, R.; OLIVARES, F. L. Promoção do crescimento do abacaxizeiro 'vitória' por ácidos húmicos e Burkholderia spp. durante a aclimatização. Revista Brasileira de Ciência do Solo, v. 34, n. 5, p. 1593-1600, 2010.

BRITO, T. S.; LIMA, W.; PAN, R.; PORFIRIO, M. D.; CANELLO, K. T.; CHAVES, E. Antagonismo de bactérias diazotróficas isoladas de plantas de milho no biocontrole de fitopatógenos. Revista Cultivando o saber, v. 11, n. 1, p. 81-91, 2018.

CAMPBELL C. L.; MADDEN L. V. Introduction to plant disease epidemiology. New York NY. John Wiley \& Sons. 1990.

CARVALHO, D. D.; MELLO, S. C.; LOBO JÚNIOR, M.; SILVA, M. C. Controle de Fusarium oxysporum $\mathrm{f}$. sp. phaseoli in vitro e em sementes, e promoção do crescimento inicial do feijoeiro comum por Trichoderma harzianum. Embrapa Arroz e Feijão-Artigo em periódico indexado (ALICE), 2011.

CASTRO, C. de; FARIAS, J. R. B. de. Ecofisiologia do girassol. Girassol no Brasil. Londrina: Embrapa Soja, v. 1, p. 501-546, 2005.

CHEN, H.; XIAO, X.; WANG, J.; WU, L.; ZHENG, Z.; YU, Z. Antagonistic effects of volatiles generated by Bacillus subtilis on spore germination and hyphal growth of the plant pathogen, Botrytis cinerea. Biotechnology Letters, v.30, p.919-923, 2008.

CONAB. Acompanhamento da safra brasileira de grãos | v. 6 - Safra 2019/20, n.12 - Décimo segundo levantamento. Companhia Nacional de Abastecimento, setembro de 2020.

DA SILVA, M. E. C. F.; DE MELO, I. S.; NASCIMENTO, R. D. S.; ROSSI, P.; RAMOS, N. Germinação e vigor de girassol com uso de bactérias promotoras de crescimento. In: Embrapa Meio Ambiente-Artigo em anais de congresso (ALICE). In: CONGRESSO INTERINSTITUCIONAL DE INICIAÇ̃̃O
CIENTÍFICA, 13., 2019, Campinas. Anais... Campinas: Instituto Agronômico, 2019. Artigo 19406, 2019. Disponivel em: http://www.alice.cnptia.embrapa.br/alice/hand le/doc/1116869. Acesso em: 27/05/2020.

DE OLIVEIRA, F. H. P. C.; SOUTO, A. M. Fisiologia de Bacillus subtilis R14: crescimento e produção de litopeptídeos em cultivos descontínuos. 2006. Dissertação (Mestrado). Programa de Pós-Graduação em Biotecnologia de Produtos Bioativos - Universidade Federal de Pernambuco, Recife.

DE SÁ, M. N. F.; DE SOUZA LIMA, J.; DE JESUS, F. N.; PEREZ, J. O.; GAVA, C. A. T. Efeito de Bacillus sp. e Trichoderma sp. no crescimento micelial de Sclerotium rolfsii. Acta Brasiliensis, v. 3, n. 2, p. 79-81, 2019a.

DENNIS, C.; WEBSTER, J. Antagonistic properties of species-groups of Trichoderma: I. Production of non-volatile antibiotics. Transactions of the British Mycological Society, v. 57, n. 1, p. 25IN3, 1971.

DIAS P. P. Controle biológico de fitopatógenos de solo por meio de isolados de fungos do gênero Trichoderma e sua contribuição no crescimento de plantas. 2011. Disponível em: https://tede.ufrrj.br/jspui/handle/jspui/2726. Acesso em: 14/05/2020.

DOMENE, M.P.; GLORIA, E.M.; BIAGI, J.; BENEDETTI, B.C.; MARTINS, L. Efeito do tratamento com óleos essenciais sobre a qualidade fisiológica e sanitária das sementes de milho (Zea mays). Arquivos do Instituto Biológico, vol. 83, p. 1-6, 2016.

ETHUR, L. Z.; BLUME, E.; MUNIZ, M.; SILVA, A. C. F.; STEFANELO, D. R.; ROCHA, E. K. Fungos antagonistas a Sclerotinia sclerotiorum em pepineiro cultivado em estufa. Fitopatologia Brasileira, v.30, n.2, p.127-133, 2005.

FERREIRA, T. C. Biocontrole de patógenos de solo e promoção de crescimento vegetal promovidos por Bacillus spp. em milho. Journal of Biology \& Pharmacy and Agricultural Management, v. 15, n. 4, 2019.

GHINI, R.; BETTIOL, W. Proteção de plantas na agricultura sustentável. Cadernos de Ciência \& Tecnologia, v. 17, n. 1, p. 61-70, 2000. 
GRAY, E. J.; SMITH, D. L. PGPR intracelular e extracelular: semelhanças e distinções nos processos de sinalização planta-bactéria. Biologia e bioquímica do solo, v. 37, n. 3, p. 395-412, 2005.

HARMAN, G. E.; HOWELL, C. R.; VITERBO, A.; CHET, I.; LORITO, M. Trichoderma species opportunistic, avirulent plant symbionts. Nature reviews microbiology, v. 2 n. 1, p. 43, 2004.

HOFFMANN, C.A.; CHAGAS, L.F.B.; SILVA, D.P.; CHAGAS JUNIOR, A.F.; SCHEIDT, G.N. Potencial de antagonismo de isolados de Trichoderma spp. contra isolados de Fusarium sp., in vitro. Revista Verde de Agroecologia e Desenvolvimento Sustentável, v. 10 n. 1 p. 236-242. 2015.

LANNA FILHO, R.; FERRO, H. M.; DE PINHO, R. S. C. Controle biológico mediado por Bacillus subtilis. Revista Trópica: Ciências Agrárias e Biológicas, v. 4, n. 2, 2010.

LAZZARO'TTO, J. J.; ROESSING, A. C.; MELLO, H. C. $\mathrm{O}$ agronegócio do girassol no mundo e no Brasil. Girassol no Brasil. Londrina: Embrapa Soja, 15-42, 2005.

LINHARES, C. M. D. S.; FREITAS, F. C. L. D.; AMBRÓSIO, M. M. D. Q.; CRUZ, B. L. S. D.; DANTAS, A. M. D. M. Efeito de coberturas do solo sobre a sobrevivência de Macrophomina phaseolina no feijão-caupi. Summa Phytopathologica, v. 42 n. 2, p. 155-159, 2015.

LOPES, M. J. S. DOS; DIAS FILHO, M. B.; CASTRO, T. H. R. DOS; FILIPPI, M. C. C.; SILVA, G. B. DA. Effect of Pseudomonas fluorescens and Burkholderia pyrrocinia on the Growth Improvement and Physiological Responses in Brachiaria brizantha. American Journal of Plant Sciences, v. 9, n. 02, p. 250, 2018.

LOURENÇO, J. C. Agronegócio brasileiro: projeções de crescimento e entraves de infra-estrutura logística. Revista Acadêmica de Economia, n. 119, p. 1-19, 2009.

LUCON, C.M.M. Promoção de crescimento de plantas com o uso de Trichoderma spp. 2009. Artigo em Hypertexto. Disponível em: <http://www.infobibos.com/Artigos/2009_1/ trichoderma/index.htm $>$. Acesso em: 16/05/2020.
LUVIZOTTTO, D. M. Caracterização fisiológica e molecular de Burkholderia spp. associadas às raízes de cana-de-açúcar. Tese de Doutorado. Universidade de São Paulo. 2008.

MACHADO, D. F. M.; PARZIANELLO, F. R.; SILVA, A. C. F. D.; ANTONIOLLI, Z. I. Trichoderma no Brasil: o fungo e o bioagente. Revista de Ciências Agrárias, v. 35 n. 1, p. 274-288, 2012.

MARRONI, I. V.; GERMANI, J. C. Eficiência de rizobactérias Bacillus spp. no controle in vitro de Macrophomina phaseolina agente etiológico da podridão de tronco da mamona (Ricinus communis L). Revista Brasileira de Agroecologia v. 6, p. 159-167, 2011.

MASSENSSINI A. M.; TÓTOLA M. R.; BORGES A. C.; COSTA M. D. Isolamento e caracterização de bactérias solubilizadoras de fosfato da rizosfera de Eucalyptus sp. Revista Árvore, v.40, n.1, p.125-134, 2016

MENEZES, M.; MACHADO, A. L. M.; DA SILVEIRA, M. D. C. V.; DA SILVA, R. L. X. Biocontrole de Macrophomina phaseolina com espécies de Trichoderma aplicadas no tratamento de sementes de feijão e no solo. Anais da Academia Pernambucana de Ciência Agronômica, v. 1, p. 133-140, 2013.

MOREIRA, R. R. Bacillus spp. Pseudomonas sp. no biocontrole de Colletotrichum do grupo acutatum, causador da mancha foliar de Glomerella em macieira. 2013. Dissertação de Mestrado Programa de Pós-Graduação em Agronomia. Departamento de Fitotecnia e Fitossanitarismo, Setor de Ciências Agrárias, Universidade Federal do Paraná.

OLIVEIRA, M. L. A.; DA SILVA PAZ, V. P.; GONÇALVES, K. S.; OLIVEIRA, G. X. S. Crescimento e produção de girassol ornamental irrigado com diferentes lâminas e diluições de água residuária. Irriga, v. 22 n., p. 204, 2018.

PARRET, A. H. A.; SCHOOFS, G.; PROOST, R.; DE MOT, R. Plant lectin-like bacteriocin from rizhosphere colonizing Pseudomonas isolate. Journal of Bacteriology, 185, p. 897-908, 2003.

PATERNIANI, E. Agricultura sustentável nos trópicos. Estudos avançados, v. 15, n. 43, p. 303-326, 2001. 
PEDRO, E. A. D. S.; HARAKAVA, R.; LUCON, C. M. M.; GUZZO, S. D. Promoção do crescimento do feijoeiro e controle da antracnose por Trichoderma spp. Pesquisa Agropecuária Brasileira, v. 47, n. 11, p. 15891595, 2012

POMELLA, A. W. V.; RIBEIRO, R. T. S. Controle biológico com Trichoderma em grandes culturasuma visão empresarial. Biocontrole de Doenças de Plantas, p. 239, 2009.

REIS, V. M.; ESTRADA-DE LOS SANTOS, P.; TENORIO-SALGADO, S.; VOGEL, J.; STOFFELS, M.; GUYON, S.; BALANDREAU, J. Burkholderia tropica sp. nov., a novel nitrogen-fixing, plant-associated bacterium. International Journal of Systematic and Evolutionary Microbiology, v. 54, n. 6, p. 2155-2162, 2004.

RIBEIRO, J. L. Manejo da cultura do girassol no Meio-Norte do Brasil. Embrapa Meio-NorteCircular Técnica (INFOTECA-E), 2008.

SANTOS, J. F. D.; SACRAMENTO, B. L. D.; MOTA, K. N. A. B.; SOUZA, J. T. D.; AZEVEDO NETO, A. D. D. Crescimento de girassol em função da inoculação de sementes com bactérias endofíticas. Pesquisa Agropecuária Tropical, v. 44, n. 2, p. 142-150, 2014.

SILVA, V. N. D.; GUZZO, S. D.; LUCON, C. M. M.; HARAKAVA, R. Promoção de crescimento e indução de resistência à antracnose por Trichoderma spp. em pepineiro. Pesquisa Agropecuária Brasileira, v. 46, n. 12, p. 1609 1618. 2011.

SILVEIRA, A. B. D. Isolamento e caracterização de linhagens de Bacillus e Paenibacillus promotores de crescimento vegetal em lavouras de arroz e trigo do Rio Grande do Sul. 2008.

SOTTERO, A. N.; dos SANTOS FREITAS, S.; de MELO, A. M. T.; TRANI, P. E. Rizobactérias e alface: colonização rizosférica, promoção de crescimento e controle biológico. Revista Brasileira de Ciência do Solo, v. 30, n. 2, p. 225-234, 2006

SOUZA JÚNIOR, I. T. D.; MOURA, A. B.; SCHAFER, J. T.; CORRÊA, B. O.; GOMES, C. B. Biocontrole da queima-das-bainhas e do nematoide-das-galhas e promoção de crescimento de plantas de arroz por rizobactérias. Pesquisa Agropecuária

Brasileira, v. 45, n. 11, p. 1259-1267, 2010.

SOUZA, A. C. A.; SOUSA, T. P.; CORTÊS, M. V. B.; RODRIGUES, F. Á.; SILVA, G. B.; FILIPPI, M. C. C. Enzyme-Induced Defense Response in the Suppression of Rice Leaf Blast (Magnaporthe Oryzae) By Silicon Fertilization and Bioagents. International Journal of Research Studies in Biosciences, v. 3, n. 5, p. 22-32, 2015.

SRINIVASAN, M.; HOLL, F. B.; PETERSEN, D. J. Influence of indoleacetic-acid-producing Bacillus isolates on the nodulation of Phaseolus vulgaris by Rhizobium etli under gnotobiotic conditions. Canadian Journal of Microbiology, v. 42, n. 10, p. 1006-1014, 1996.

SU, G.; SUH, S. O.; SCHNEIDER, R. W.; RUSSIN, J. $\mathrm{S}$. Host specialization in the charcoal rot fungus, Macrophomina phaseolina. Phytopathology, v. 91, n. 2, p. 120-126, 2001.

TESSO, T.; EJETA, G. Stalk strength and reaction to infection by Macrophomina phaseolina of brown midrib maize (Zea mays) and sorghum (Sorghum bicolor). Field Crops Research. Estados Unidos, v.120, p.271-275, 2011.

YABUUCHI, E.; KOSAKO, Y.; OYAIZU, H.; YANO, I.; HOTTA, H.; HASHIMOTO, Y.; EZAKI, T.; ARAKAWA, M. Proposal of Burkholderia gen. nov. and tranfer of seven species of the genus Pseudomonas homology group II to the new genus, with the type species Burkholderia cepacia (Palleroni and Holmes 1981) comb. nov. Microbiology and Immunology, Tokyo, v. 36, p. 1251-1275, 1992.

YEDIDIA, I.; SHORESH, M.; KEREM, Z.; BENHAMOU, N.; KAPULNIK, Y.; CHET, I. Concomitant induction of systemic resistance to Pseudomonas syringae pv. lachrymans in cucumber by Trichoderma asperellum (T-203) and accumulation of phytoalexins. Applied and Environmental Microbiology, v. 69, n. 12, p. 7343-7353, 2003.

ZOBIOLE, L. H. S.; CASTRO, C. de; OLIVEIRA, F. A. de; OLIVEIRA JUNIOR, A. de. Marcha de absorção de macronutrientes na cultura do girassol. Revista Brasileira de Ciência do Solo, Viçosa, v. 34, p. 425-433, 2010. 